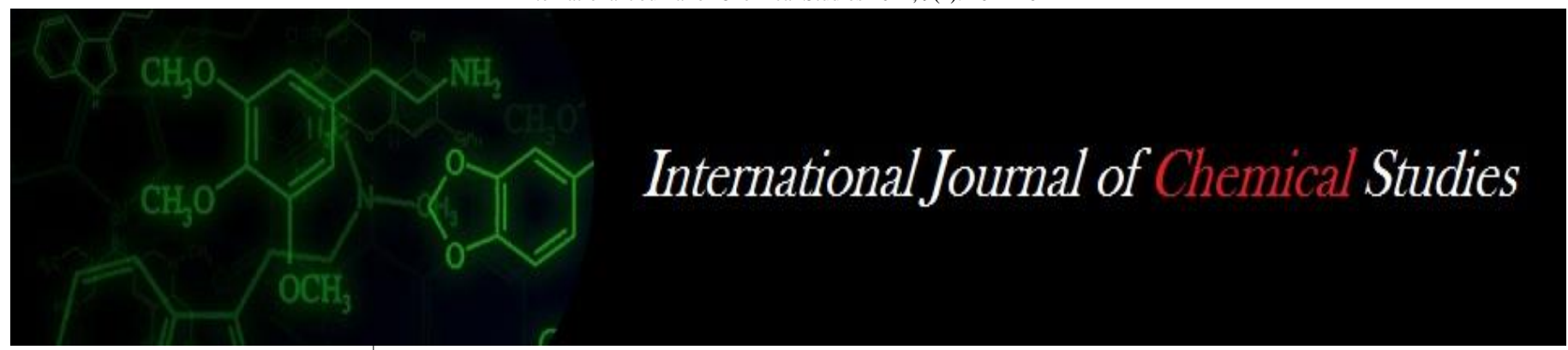

P-ISSN: 2349-8528

E-ISSN: 2321-4902

www.chemijournal.com

IJCS 2021; 9(1): 2621-2624

(C) 2021 IJCS

Received: 02-10-2020

Accepted: 11-11-2020

Pinki Meena

SKN College of Agriculture,

SKN Agriculture University,

Jobner, Jaipur, Rajasthan, India

BS Chandrawat

SKN College of Agriculture,

SKN Agriculture University,

Jobner, Jaipur, Rajasthan, India

RR Ahir

SKN College of Agriculture,

SKN Agriculture University,

Jobner, Jaipur, Rajasthan, India

Shivam Maurya

SKN College of Agriculture,

SKN Agriculture University,

Jobner, Jaipur, Rajasthan, India

Lalita Lakhran

SKN College of Agriculture,

SKN Agriculture University,

Jobner, Jaipur, Rajasthan, India

Satydev Prajapati

SKN College of Agriculture,

SKN Agriculture University,

Jobner, Jaipur, Rajasthan, India

Chetan Kumar Kumawat

SKN College of Agriculture,

SKN Agriculture University,

Jobner, Jaipur, Rajasthan, India

Corresponding Author:

Pinki Meena

SKN College of Agriculture,

SKN Agriculture University,

Jobner, Jaipur, Rajasthan, India

\section{Effect of Fusarium oxysporum f. sp. lycopersici and Meloidogyne incognita interaction on wilt disease incidence in tomato}

\author{
Pinki Meena, BS Chandrawat, RR Ahir, Shivam Maurya, Lalita Lakhran, \\ Satydev Prajapati and Chetan Kumar Kumawat
}

DOI: $\underline{\text { https://doi.org/10.22271/chemi.2021.v9.i1ak.11621 }}$

\begin{abstract}
Development of diseases in cultivated crops depends on the complex inter-relationship between host, pathogen and prevailing environmental conditions. The significant role of nematodes in the development of nematode-fungus interaction is demonstrated in many crops throughout the world. Therefore, the main objectives of this study were to evaluate the interaction between Fusarium oxysporum f. sp. lycopersici and Meloidogyne incognita. The experiment was laid out in a completely randomized design (CRD) with three replications in pot conditions. The results show that inoculation of nematode at $7^{\text {th }}$ day prior to inoculation of fungus caused maximum reduction in plant growth parameters and increase per cent disease incidence followed by simultaneous inoculation of nematode and fungus as compared to control.
\end{abstract}

Keywords: Tomato, wilt, Fusarium, meloidogyne, interaction

\section{Introduction}

Tomato (Solanum lycopersicum L.) is one of the most popular and widely grown vegetable crops in the world and universally treated as "Protective food" [1]. India ranks second in the area as well as in production of Tomato. In India, it is being grown in about 7.67 lakh hectares with an annual production of 163.85 lakh metric tonnes. Tomato crop suffers from various phytopathogenic diseases. Among the fungal diseases, wilt disease caused by Fusarium oxysporum f. sp. lycopersici is most important disease and is limiting factor in tomato production. The fungus also develops synergistic relationship with Meloidogyne spp. leading to root-knot wilt disease complex. This complex is highly destructive to tomato plants and is characterized by enhanced wilt symptoms. Wilt disease of tomato one of the economically most important diseases in major tomato growing regions worldwide ${ }^{[2]}$. It is a highly destructive pathogen, causing 10 to $50 \%$ yield loss in many tomato production areas ${ }^{[3]}$. However, the widespread use of chemicals fungicides has been a subject of public concern and security due to their potentially harmful effects on environment and human health and their undesirable effect on non-target organisms ${ }^{[4]}$. Obtaining optimum crop quality and economic production of tomato depends on development and exploitation of an eco-friendly, sustainable, economical and alternative methods of nematode-wilt disease complex management. Being aware of the array of organisms influencing the crop and the nature of various organisms' interactions is therefore essential. The main objectives of this research work were to: (i) investigate the effect of the interaction between Meloidogyne incognita (MI) and Fusarium oxysporum f. sp. lycopersici (FOL) on tomato based on their order of inoculation.

\section{Material and Methods}

An experiment was carried out in pots holding $1 \mathrm{~kg}$ of soil. The treatments consisted of Nematode alone (N), Fungus alone (F), Simultaneous inoculation of Nematode and Fungus $(\mathrm{N}+\mathrm{F})$, Nematode at the time of sowing and Fungus one week after $(\mathrm{N} 1+\mathrm{F} 2)$, Fungus at the time of sowing and Nematode after one week $(\mathrm{F} 1+\mathrm{N} 2)$ and Control without Fungus and Nematode. Tomato variety Pusa Ruby was used for the present studies. A constant level of 2000 second stage juveniles was inoculated per pot (i.e. $\mathrm{N}, \mathrm{N}+\mathrm{F}, \mathrm{N} 1+\mathrm{F} 2, \mathrm{~F} 1+\mathrm{N} 2$ ). The Inoculating soil with fungus, Fusarium oxysporum, $20 \mathrm{~g}$ content of each flask containing 
sorghum grain inoculated with the fungus was mixed in each pot (i.e. $\mathrm{F}, \mathrm{N}+\mathrm{F}, \mathrm{N} 1+\mathrm{F} 2, \mathrm{~F} 1+\mathrm{N} 2$ ). When the fungus and nematode was to be inoculated one week after nematode/fungus inoculation, the technique suggested by Grewal and Pall (1974) was adopted with slight modification of placing three glass rods equidistant in a circle of two $\mathrm{cm}$ diameter and plugging the holes with sterile soil after introducing the actively growing Fusarium oxysporum derived from the sorghum grain and the nematodes were pipetted around the seedlings. Due precautions were observed to avoid contamination from one pot to another. A total of 30 pots were thus randomized over the glass house bench following CRD and watered daily with an equal quantity of sterilized distilled water if when required. The experiment was concluded after 45 days after Inoculation. Observations on plant growth characters, nematode reproduction and PDI were recorded.

\section{Experiments result}

Interaction between Fusarium oxysporum f. sp. lycopersici and Meloidogyne incognita on disease incidence

Root knot disease caused by Meloidogyne incognita and wilts disease caused by Fusarium oxysporum f. sp. lycopersici and interacting with each other to develop Root knot wilt disease complex which was highly destructive to tomato plants. All the stages of Meloidogyne incognita were harmful and developed root galls symptoms on roots (Plate 3 and 4). The data on interaction studies between Fusarium oxysporum $\mathrm{f}$. sp. lycopersici and Meloidogyne incognita.

\section{Shoot Length}

The data indicated that shoot length in control was recorded $43.55 \mathrm{~cm}$. Among all the treatments minimum shoot length was recorded $20.15 \mathrm{~cm}$ when nematode inoculated first and fungus inoculated seven days after, whereas maximum shoot length was recorded $32.75 \mathrm{~cm}$ when fungus inoculated alone followed by $(31.38 \mathrm{~cm})$ Nematode inoculation alone and $(25.13 \mathrm{~cm})$ fungus inoculated first and nematode inoculated seven days after.

\section{Root Length}

Similar trend was also noted with the length of roots. Among all the treatments minimum root length was recorded $7.08 \mathrm{~cm}$ when nematode inoculated first and fungus inoculated seven days after, whereas maximum root length was recorded 10.50 $\mathrm{cm}$ when fungus inoculated alone followed by $(9.71 \mathrm{~cm})$ in nematode inoculation alone and $(9.43 \mathrm{~cm})$ fungus inoculated first and nematode inoculated seven days after. However, highest root length $(12.62 \mathrm{~cm})$ in un-inoculated control.

\section{Shoot Weight}

The data indicated that shoot weight in control was recorded $25.47 \mathrm{~g}$. Among all the treatments on fresh shoot basis minimum shoot weight was recorded $3.92 \mathrm{~g}$ when nematode inoculated first and fungus inoculated seven days after, whereas maximum shoot weight was recorded $12.64 \mathrm{~g}$ when nematode inoculated alone followed by (11.91 g) fungus inoculation alone and $(8.84 \mathrm{~g})$ fungus inoculated first and nematode inoculated seven days after.

Table 1: Interaction between Fusarium oxysporum f. sp. lycopersici and Meloidogyne incognita on disease incidence

\begin{tabular}{|c|c|c|c|c|c|c|c|c|c|}
\hline \multirow{2}{*}{ Treatments } & \multirow{2}{*}{$\begin{array}{l}\text { Shoot length } \\
\text { (cm) }\end{array}$} & \multirow{2}{*}{\begin{tabular}{|c|}
$\begin{array}{c}\text { Root Length } \\
\text { (cm) }\end{array}$ \\
\end{tabular}} & \multicolumn{2}{|c|}{ Shoot weight (g) } & \multicolumn{2}{|c|}{ Root weight (g) } & \multirow{2}{*}{\begin{tabular}{|c|}
$\begin{array}{c}\text { No of Galls/ } \\
\text { plant }\end{array}$ \\
\end{tabular}} & \multirow{2}{*}{$\begin{array}{c}\text { No of egg } \\
\text { Masses/ plant }\end{array}$} & \multirow{2}{*}{ PDI } \\
\hline & & & Fresh & Dry & Fresh & Dry & & & \\
\hline $\mathrm{N}$ & 31.38 & 9.71 & 12.64 & 1.92 & 2.24 & 0.86 & 44.75 & 31.00 & $0.00(0.00)$ \\
\hline $\mathrm{F}$ & 32.75 & 10.50 & 11.91 & 1.85 & 1.97 & 0.78 & 0.00 & 0.00 & $49.99(45.00)$ \\
\hline $\mathrm{N}+\mathrm{F}$ & 22.89 & 8.98 & 5.96 & 0.71 & 0.81 & 0.56 & 35.50 & 25.75 & $55.53(48.17)$ \\
\hline $\mathrm{N} 1+\mathrm{F} 2$ & 20.15 & 7.08 & 3.92 & 0.51 & 0.70 & 0.50 & 42.00 & 23.75 & $61.25(51.51)$ \\
\hline $\mathrm{F} 1+\mathrm{N} 2$ & 25.13 & 9.43 & 8.84 & 0.79 & 1.11 & 0.62 & 28.25 & 16.75 & $52.26(46.30)$ \\
\hline Control & 43.55 & 12.62 & 25.47 & 4.18 & 5.31 & 1.33 & 0.00 & 0.00 & $0.00(0.00)$ \\
\hline S.Em \pm & 0.711 & 0.676 & 0.552 & 0.222 & 0.361 & 0.061 & 1.698 & 0.718 & 0.856 \\
\hline $\mathrm{CD}$ at $5 \%$ & 2.113 & 2.010 & 1.640 & 0.660 & 1.072 & 0.181 & 5.046 & 2.133 & 2.544 \\
\hline
\end{tabular}

Average of five replications

Figures given in parenthesis are angular transformed values

$\mathrm{N}=$ Nematode alone, $\mathrm{F}=$ Fungus alone, $\mathrm{N}+\mathrm{F}=$ Simultaneous inoculation of Nematode and Fungus,

$\mathrm{N} 1+\mathrm{F} 2=$ Nematode at the time of sowing and Fungus seven days after, F1+N2 = Fungus at the time of sowing and Nematode seven days after, Control $=$ without Nematode and Fungus

Among all the treatments on dry shoot basis minimum shoot weight was recorded $0.51 \mathrm{~g}$ when nematode inoculated first and fungus inoculated seven days after, whereas maximum shoot weight was recorded $1.92 \mathrm{~g}$ when nematode inoculated alone followed by $(1.85 \mathrm{~g})$ fungus inoculation alone and (8.84 g) fungus inoculated first and nematode inoculated seven days after. However, highest shoot weight (4.18) in un-inoculated control.

\section{Root Weight}

The data indicated that root weight in control was recorded $5.31 \mathrm{~g}$. Among all the treatments on fresh root basis minimum root weight was recorded $0.81 \mathrm{~g}$ when nematode inoculated first and fungus inoculated seven days after, whereas maximum root weight was recorded $2.24 \mathrm{~g}$ when nematode inoculated alone followed by $(1.97 \mathrm{~g})$ fungus inoculation alone and $(1.11 \mathrm{~g})$ fungus inoculated first and nematode inoculated seven days after.
Among all the treatments on dry root basis minimum root weight was recorded $0.50 \mathrm{~g}$ when nematode inoculated first and fungus inoculated seven days after, whereas maximum root weight was recorded $0.86 \mathrm{~g}$ when nematode inoculated alone followed by $(0.78 \mathrm{~g})$ fungus inoculation alone and $(0.62$ g) fungus inoculated first and nematode inoculated seven days after. However, highest root weight $(1.33 \mathrm{~g})$ in un inoculated control.

\section{Number of Root Galls per plant}

Among all the treatments maximum no. of root galls (44.75) were recorded in nematode inoculated alone whereas minimum no. of root galls (28.25) were recorded in fungus inoculated first and nematode inoculated seven days after. In case of nematode inoculated first and fungus inoculated seven days after no. of root galls were 42 whereas simultaneous inoculation of nematode and fungus no. of root galls were recorded 35.50 . 


\section{Number of Egg masses per plant}

Among all the treatments maximum no. of egg masses (31) were recorded in nematode inoculated alone whereas minimum no. of egg masses (16.75) were recorded in fungus inoculated first and nematode inoculated seven days after. In case of nematode inoculated first and fungus inoculated seven days after no. of egg masses were 23.75 whereas, simultaneous inoculation of nematode and fungus no. of egg masses were recorded 25.75 as compared to control.
Percent disease incidence: Among all the treatments highest per cent disease incidence of wilt was recorded $61.25 \%$ when nematode inoculated first and fungus inoculated seven days after whereas, lowest per cent disease incidence of wilt recorded $49.99 \%$ when fungus inoculated alone. In case of nematode and fungus inoculated simultaneously per cent disease incidence of wilt was $55.53 \%$ whereas, the treatment in which fungus inoculated first and nematode a week after showed $52.26 \%$ disease incidence of wilt.
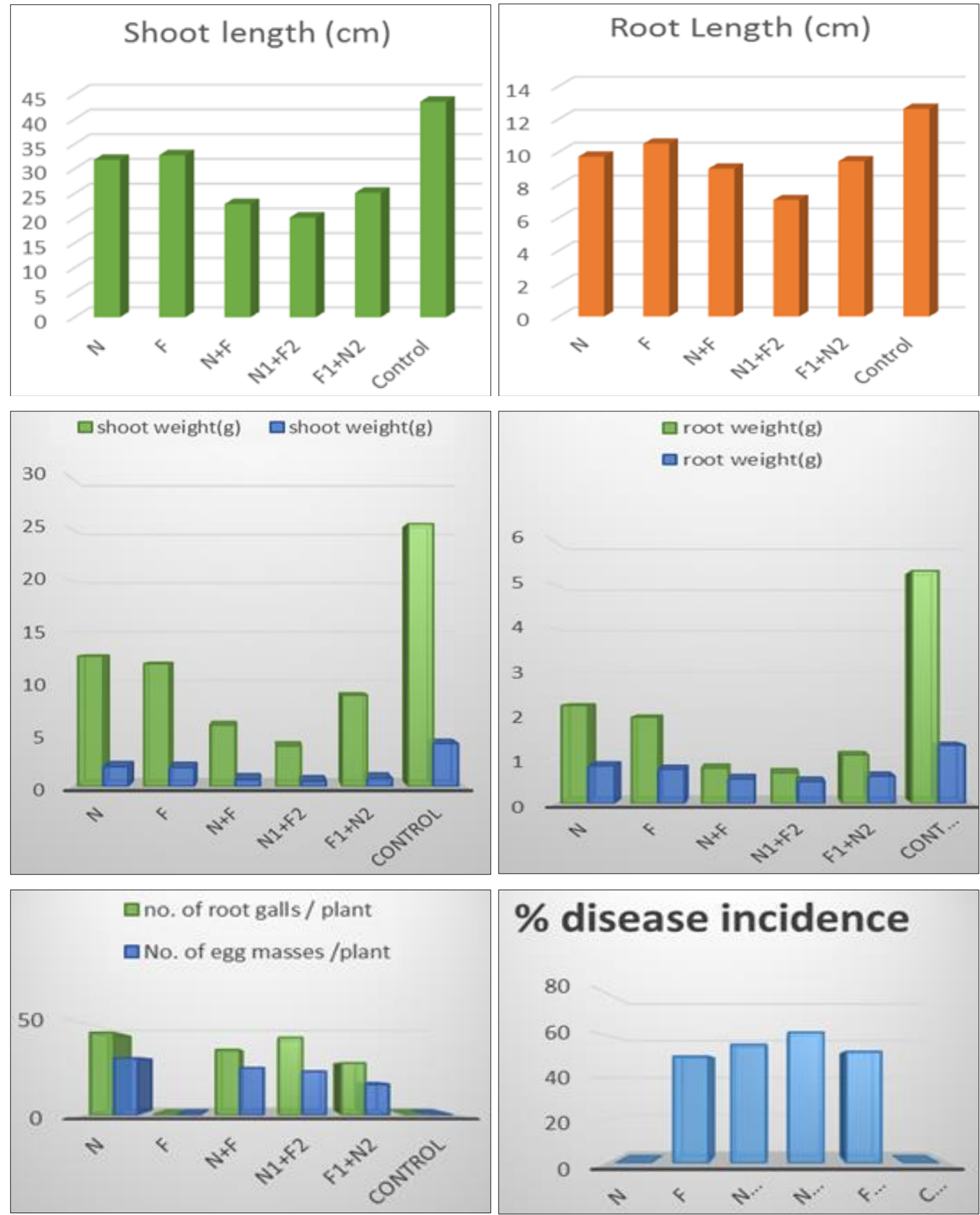

\section{$\%$ disease incidence}

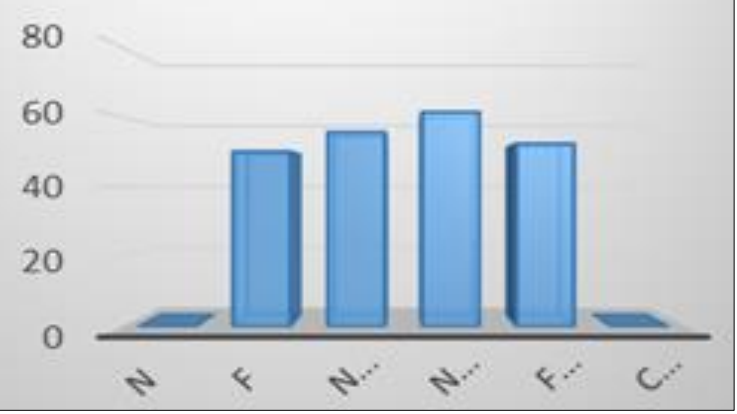

Fig 1: Interaction between Fusarium oxysporum f. sp. lycopersici and Meloidogyne incognita on disease incidence

\section{Discussion}

The complex relationship between the Meloidogyne incognita and Fusarium oxysporum f. sp. lycopersici affected plant status and caused maximum reduction in plant growth parameter and highest per cent disease incidence was recorded when nematode inoculated prior to fungus 
inoculation. In interaction studies, inoculation of nematode 7 days prior to inoculation of fungus caused maximum reduction in plant growth parameters and increase per cent disease incidence followed by simultaneous inoculation of nematode and fungus as compared to control. These results suggest that the nematode predisposes the tomato to infection by wilt inducing fungus Fusarium oxysporum f. sp. lycopersici and aggravate the disease by modifying the physiological environment of the root system of tomato, as reduction in wilt incidence and number of galls observed in situations where fungus inoculated prior to nematode inoculation. Similar findings were reported many researcher's $[5,6,7,8,9,10]$. Sharma and McDonald, $1990^{[11]}$ also reported that the presence of Meloidogyne spp aggravated the disease situation by $F$. oxysporum f. sp. ciceri on chickpea. Presence of nematodes not only predisposed the host but also shortened the incubation period for disease expression. Similar findings were observed by Fazal et al., $1994^{[12]}$ and Malhotra et al., $2011^{[13]}$. Similar type of reduced galling and population density in presence of $F$. oxysporum was also reported by Roy and Mukhopadhya $2004^{[14]}$.

\section{References}

1. Thamburaj S, Singh N. Text book of Vegetables, Tuber crops and Spices, Indian Council of Agriculture Research Publications, New Delhi 2013, 309.

2. Abdallah RA. Biocontrol of Fusarium wilts and growth promotion of tomato plants using endophytic bacteria isolated from Solanum elaeagnifolium stems. Journal of Phytopathology 2016;164(10):811-824.

3. Ghazalibiglar H. Biological control of Fusarium wilt of tomato by Trichoderma isolates. New Zealand Plant Protection 2016;69:57-63.

4. Bisen K, Keswani C, Mishra S, Saxena A, Rakshit A, Singh HB. Unrealized potential of seed biopriming for versatile agriculture. In Nutrient Use Efficiency: from Basics to Advances (ed. A. Rakshit, H. B. Singh, A. Sen), Springer India 2015, 193-206.

5. Bhagawati B, Goswami BK. Interaction of Meloidogyne incognita and Fusarium oxysporum f. sp. lycopersici on tomato. Indian Journal of Nematology 2000;30(1):93-94.

6. Akram MA, Khan MR. Interaction of Meloidogyne incognita and Fusarium oxysporum f.sp. Lycopersici on tomato. Annual Plant Protection Science 2006;14(2):448451.

7. Ganaie MA, Khan TA. Studies on the interactive effect of Meloidogyne incognita and Fusarium solani on Lycopersicon esculentum, Mill. International Journal of Botany 2011;7(2):205-208.

8. Meena SK, Ramyabharathi SA, Raguchander T, Jonathan EI. Meloidogyne incognita and Fusarium oxysporum interaction in Gerbera. African Journal of Microbiology Research 2015;9(18):1281-1285.

9. Kumar D, Bhatt J, Sharma RL. Efficacy of Different Bio Control Agents against Meloidogyne incognita and Fusarium oxysporum on Black gram (Vigna mungo L). International Journal of Current Microbiology and Applied Sciences 2017a;6(8):2287-2291.

10. Kumar D, Bhatt J, Sharma RL, Kumar N. Interaction between Meloidogyne incognita and Fusarium oxysporum on Black gram (Vigna mungo L). International Journal of Chemical Studies 2017b;5(4):624-627.

11. Sharma SB, McDonald D. Global status of nematode problems of groundnut, pigeon pea, chickpea, sorghum and pearl millet and suggestions for future work. Crop Protection 1990;9:453-458.

12. Fazal M, Khan MI, Rara MMA, Siddiqi ZA. Interaction between Meloidogyne incognita and Fusarium oxysporum f.sp. lentis on lentil. Nematologia mediterranea 1994;22:185-187.

13. Malhotra A, Agarwal T, Trivedi PC. In vitro efficacy of various fungal and bacterial antagonists against Rhizoctonia solani, causal agent of damping off disease in Capsicum annuum. Int. J Pharma. Biol. Sci 2011;3(2):288-292.

14. Roy K, Mukhopadhyay AK. Interaction of Macrophomina phaseolina and Meloidogyne incognita on brinjal. Annual Plant Protection Science 2004;12:253236. 